Elsevier Editorial System(tm) for European Review of Applied Psychology / Revue Européenne de Psychologie Appliquée Manuscript Draft

Manuscript Number:

Title: Does "chaining" always really work towards compliance gaining? The case of the "but you are free" technique and social proof applied to charitable donation

Article Type: Original article

Keywords: evocation of freedom; descriptive norm; compliance gaining; money donation; meta-analysis

Corresponding Author: Dr. alexandre pascual,

Corresponding Author's Institution: univ. bordeaux

First Author: alexandre pascual

Order of Authors: alexandre pascual; thomas salanova; ikram bouhassine; cedric denis-remis; daniel priolo; fabien girandola; nicolas guéguen

Abstract: The chaining procedure consists in linking together two or more compliance gaining strategies in order to obtain greater behavioral compliance. In two studies we tested chaining that included two compliance gaining procedures: the "but you are free" technique (BYAF) and social proof (SP). A total of 2204 passersby were approached in different countries (France, Tunisia, China and Moldavia). They were asked to donate money for cancer research with, respectively, a control formulation, a BYAF formulation, a SP formulation or a BYAF + SP formulation. Results indicate that chaining did not work because the BYAF + SP condition produced the same behavioral compliance as BYAF or SP separately (studies 1 and 2). Furthermore, we analyzed the participants' justifications after complying with or rejecting the request and the reasons were substantially the same under each condition (study 2). Failure to observe the chaining process is interpreted through theoretical explanations whereby BYAF and SP are antagonistic.

Suggested Reviewers: valérie fointiat valerie.fointiateuniv-lorraine.fr spécialiste de l'influence sociale

jerry burger

jburgerescu. edu

social influence specialist

Opposed Reviewers: 
Does "chaining" always work towards compliance gaining? The case of the "but you are free" technique and social proof applied to charitable donation

Alexandre Pascual ${ }^{1}$,

Thomas Salanova

Ikram Bouhassine ${ }^{2}$

Cedric Denis-Remis ${ }^{3}$

Daniel Priolo ${ }^{4}$

Fabien Girandola ${ }^{2}$

Nicolas Guéguen ${ }^{5}$

${ }^{1}$ University of Bordeaux

2

Aix Marseille University

${ }^{3}$ MINES ParisTech, PSL Research University

4

University of Nice Côte d'Azur, LAPCOS

5

University of South Britain

\section{*Correspondence}

Alexandre Pascual, Department of Psychology,

University of Bordeaux, 3ter Place de la Victoire, 33076 Bordeaux cedex.

E-mail: alexandre.pascual@u-bordeaux.fr

Phone number: +33557573026 
Social Proof and «But you are Free »

\title{
Does "chaining" always work towards compliance gaining? The case of the "but you are free" technique and social proof applied to charitable donation
}

\begin{abstract}
The chaining procedure consists in linking together two or more compliance gaining strategies in order to obtain greater behavioral compliance. In two studies we tested chaining that included two compliance gaining procedures: the "but you are free" technique (BYAF) and social proof (SP). A total of 2204 passersby were approached in different countries (France, Tunisia, China and Moldavia). They were asked to donate money for cancer research with, respectively, a control formulation, a BYAF formulation, a SP formulation or a BYAF + SP formulation. Results indicate that chaining did not work because the BYAF + SP condition produced the same behavioral compliance as BYAF or SP separately (studies 1 and 2). Furthermore, we analyzed the participants' justifications after complying with or rejecting the request and the reasons were substantially the same under each condition (study 2). Failure to observe the chaining process is interpreted through theoretical explanations whereby BYAF and SP are antagonistic.
\end{abstract}

Key words: evocation of freedom, descriptive norm, compliance gaining, money donation, meta analysis

\section{Introduction}

Social psychology provides a wealth of compliance gaining strategies to influence behavior (Pratkanis, 2007; Dolinski, 2016 for a review). The chaining process consists in linking together two or more compliance gaining techniques in order to obtain greater behavioral compliance. It follows that the combined use of two techniques based on different 
theoretical principles will be more effective in producing compliance than the use of either one alone (Howard, 1995). For example, chaining is effective when combining foot-in-the door and social labeling (Goldman, Seever \& Seever, 1982), foot-in-the-door and door-in-theface (Goldman, 1986), foot-in-the-door and low ball (Joule, 1987), door-in-the-face and footin-the-mouth (Fointiat, 2000), social proof and "even a penny will help" (Shearman, \& Yoo, 2007), foot-in-the-door and "but you are free" technique (Dufourcq-Brana, Pascual \& Guéguen, 2006; Guéguen, Meineri, Martin \& Grandjean, 2010), touch and "but you are free" technique (Samson, 2009). However, relatively few publications have directly tested the chaining process in the scientific literature because social psychologists have principally focused on testing single or competing theoretical explanations of compliance gaining.

Furthermore, Pascual, Felonneau, Guéguen \& Lafaille (2014) failed to obtain a chaining effect when combining two particular strategies: the "but you are free" technique (BYAF) and social proof (SP). In their study, they tried to induce smokers to drop their cigarette butts in an ashtray rather than on the ground. SP was operationalized with a sign placed above ashtrays; this sign mentioned that most people throw their cigarette butts in the ashtrays. The BYAF technique was operationalized with a sign mentioning that people were free to throw their cigarette butt in the ashtray. In a third condition the sign contained SP + BYAF messages. Finally, in a control condition, no sign was present. Results indicated that the combined effect of SP + BYAF was no more effective than SP or BYAF alone. The authors concluded that it is theoretically conceivable that the combinations of SP and BYAF do not necessarily lead to an additive effect. Influence is characterized by a source and a target. However, although the source of influence is external to smokers within the framework of SP (behavior of the majority), it is internal within the framework of the BYAF message. In paradigms of compliance without pressure (such as BYAF), the source of influence is the subject himself because he believes that he is the originator of his own behavior and is not under any external 
pressure. On this basis, the authors argued that SP and BYAF could in fact be two opposing processes of influence. In order to accurately outline this assumption, the following sections will provide an overview of the SP and BYAF principles.

\section{Normative social influence and Social Proof (SP)}

Originally, conformity (or majority influence) refers to the change in behavior that can be observed in an individual, who is then referred to as the target, in the direction of the behaviors displayed by other persons considered to be sources of influence or the majority group (Asch, 1951). Conformity is generally explained by the theory of normative influence. Although the influence of social norms, i.e. social proof, on the behavior of individuals has been known to social psychologists for several decades (Cialdini \& Goldstein, 2004; Goldstein \& Cialdini, 2007), a distinction has been made between two types of social norms with, on the one hand, injunctive norms and, on the other, descriptive norms (Ciadini, Reno \& Kallgren, 1990). The former involves the perceptions that an individual manifests concerning the degree of agreement or disagreement with others regarding a specific course of action. The latter refers to the perceptions concerning the actual behavior of others. Thus, the simple fact of giving prominence to social norms can influence the behavior of individuals in the direction of these norms (Cialdini, 2003). On the basis of research covering SP (descriptive norm), simply stating that others have displayed a given behavior could influence a given individual to adopt the aforementioned behavior himself or herself. Although people underestimate the extent to which their actions are determined by actions of others (Cialdini, 2005), they perceive this influence (Nolan, Schultz, Cialdini, Goldstein, \& Griskevicius, 2008). Biel, Borgstede and Dahlstrand, (1999) present social norms as an external pressure. Thøgersen (2006) suggests that social norms represent a purely external, non-internalized, form of behavioral regulation. Moreover this author argues that descriptive norms are in fact 
less integrated to the self than other types of norms.

In light of these findings, we consider that SP constitutes an external pressure to participants where others' behavior is the source and the participant is the target.

\section{Compliance without pressure and "but you are free" technique (BYAF)}

Compliance without pressure first appeared with Freedman and Fraser (1966) in their publication on the foot-in-the-door technique. It is a set of techniques "likely to induce people to do what is expected of them of their own volition" (Joule \& Beauvois, 1998, p. 29). Under these procedures, individuals express various behaviors under the impression of acting of their own free will, from the use of the term compliance without pressure. The BYAF technique (Guéguen \& Pascual, 2000) is a paradigm of compliance without pressure. The principle is simple: a request made to someone with the added proposal of BYAF will significantly increase the acceptance of said request. The simple verbal inference of a feeling of freedom will thus encourage the compliance of individuals with various types of requests. (Guéguen, Joule, Halimi-Falkowicz, Pascual, Fischer-Lokou \& Dufourcq-Brana, 2013). To explain this effect, two non-exclusive theories can be put forward: the theory of commitment (Kiesler, 1971) and the theory of psychological reactance (Brehm, 1966).

According to Kiesler, several factors enable an increase in the degree of commitment of individuals in their actions. Among these factors, the feeling of freedom is, according to the author, one of the most powerful. So, the more an individual is placed in a context of freedom when he carries out a behavior, the more strongly he is committed to that behavior. But "there is nothing easier than creating a context of freedom. You need only accompany the request made to the actor with a phrase asserting that he is free to do what is expected of him, or not. We believe this phrase to be one of the most fascinating in scientific literature." (Joule \& Beauvois, 1998, p. 71) Thus, in the case of a request for money made by a stranger in the 
street, for instance, when subjects are declared to be free to act, not only do they most often

agree to the request, but they also show themselves to be more generous in giving than those in a controlled condition (Guéguen et al., 2013). Indeed, it is as if the context of freedom generated by the proposal BYAF binds subjects more to the expected altruistic behavior, which translates into higher average amounts given.

But the theory of psychological reactance (Brehm, 1966) can also help us to interpret the effects produced by the BYAF technique. Reactance is characterized by a negative state of motivation following a (supposedly real) threat of restriction of individual freedom and this translates into a resistance to the influence. This theory therefore reasons that the threat or actual loss of freedom will motivate the individual to restore that freedom. So, when individual $\mathrm{A}$ formulates a request to individual $\mathrm{B}$, it is probable that in most cases $\mathrm{B}$ is likely to feel reactance because A is trying to "dictate" to B the behavior to be executed. There is, therefore, in some way a suggestion of restriction of B's freedom. At this stage, in order to recover his freedom, B would tend to reject A's request. But, if A adds the phrase "but you are free to..." to his proposal, it is highly likely that B's rate of reactance will be significantly lower, which would translate into a more probable acceptance of the request. It is important to emphasize that the two theories that we have just mentioned are in no way mutually incompatible.

We consider that BYAF constitutes internal pressure to an individual because this kind of message refers directly to the subject's own will (source), and the subject is also the target of the influence.

\section{Overview}

We argue that SP and BYAF processes are related to different sources of influence. As Freedman and Fraser wrote (1966), “Work on attitude change, conformity, imitation, and 
obedience has all tended to stress the importance of the degree of external pressure" (p. 195).

Clearly, under most circumstances, the more pressure applied (with SP for example), the more likely individuals will comply. On the other hand, BYAF is a "compliance without pressure" technique. This kind of technique implies that "factors other than external pressure are often quite critical in determining degree of compliance" (Freedman \& Fraser, 1966, p. 195). Although the BYAF technique could reduce reactance in a subject, SP could induce a normative pressure indicating the behavior to be adopted. Because of this contradiction, the two processes will probably not have any additional effect on compliance.

Finally, because of a potential antinomy between external pressure (SP) and internal pressure (BYAF), it is possible that the two kinds of influence sources (internal vs external) produce a non-additive effect on compliance; whereas in the framework of a chaining hypothesis, the higher the number of influence sources, the higher people's compliance will be.

In order to verify that the chaining effect does not work when SP and BYAF are combined, two studies were conducted. In the first study, the interaction between SP and BYAF was tested in a field setting consisting in asking for money from passersby in the street to help cancer prevention and detection. Study 2 was a replication of study 1, but in addition participants were asked to give a justification for their acceptance or rejection of the request. This was an exploratory method in order to determine whether or not justifications differed among influence sources, i.e. the compliance gaining strategies used.

\section{Study 1}

\section{Method}




\section{Participants}

A total of 628 male and female passersby (308 Chinese and 320 French) between 20 and 60 years of age $(M=38.15 ; S D=10.9)$ participated in the study.

\section{Procedure}

Twelve Chinese students ( 6 males and 6 females between 20 and 33 years old) and one female French student (22 years old) were the experimenters in their respective countries. They were instructed to approach passersby that were alone in pedestrian streets in the cities of Shanghai, China, and Bordeaux, France (two urban cities) to ask them to give money for cancer prevention and detection (dependent variable). The experimental design contains two independent variables: SP (presence/ absence) and BYAF (presence/absence). So the experimenters formulated their request in one of the following four ways:

Control formulation: "Hello Madam / Sir, the Association $X^{1}$ is collecting donations for cancer prevention and detection, would you help us please?"

Social Proof formulation: "Hello Madam / Sir, the Association X is collecting donations for cancer prevention and detection, many people have already made donations to the association, would you help us please?"

BYAF formulation: "Hello Madam / Sir, the Association X is collecting donations for cancer prevention and detection, would you help us please? But of course, you are free to accept or refuse."

Social Proof + BYAF formulation: "Hello Madam / Sir, the Association X is collecting donations for cancer prevention and detection, many people have already made donations to the association, would you help us please? But of course, you are free to

\footnotetext{
${ }^{1}$ In each country, the name of a specific association was given
} 
accept or refuse."

\section{Results}

The first passerby was assigned to the first condition, the second passerby to the second condition, the third passerby to the third condition, the fourth passerby to the fourth condition, the fifth passerby to the first condition, and so one.

Participants who went on their way before the experimenter finished reciting the formulation where not accounted for in the study. Participants who directly donated money to the experimenter were counted as compliant participants and those who did not as noncompliant participants. Experimenters noted on a sheet whether participants agreed or not with the request.

A $2(\mathrm{SP}) \times 2(\mathrm{BYAF}) \times 2($ country $) \times 2$ (participant gender) binary logistic regression was performed using the participants' acceptance to donate as the dependent variable. Only two significant effects appeared.

A country main effect was statistically significant, Wald $(1)=9.30, p<.001$. More participants agreed to the request in France (25.6\%) than in China (14.6\%).

A significant interaction between SP and BYAF was observed, Wald $(1)=6.51, p<.01$. Figure 1 displays the percentage of those in each condition who agreed to give money for cancer prevention and detection. To analyze this effect of interaction, we compared each condition to each other with $\chi^{2}$ of Pearson; only two significant effects were observed.

The BYAF condition generated more compliance than the control condition $\left(\chi^{2}(1,314)\right.$ $=10.88 ; p=.001 ; \varphi=.19 ; O R=2.63)$. In the same way, SP generated more compliance than the control condition $\left(\chi^{2}(1,315)=4.49 ; p=.03 ; \varphi=.12 ; O R=1.91\right)$.

None of the other main effects or interactions were statistically significant either. 
Insert here figure 1

\section{Discussion}

Study 1 failed to observe a chaining effect between SP and BYAF. Furthermore, the SP + BYAF combination had no effect on compliance comparatively to the control condition whereas simple effects were observed with SP and BYAF separately.

Such results are consistent with our main hypothesis, namely that because of an antinomy between external pressure (SP) and internal pressure (BYAF), it is possible that the two kinds of influence sources (internal vs external) produce a non-additive effect on compliance; whereas in the framework of a chaining hypothesis, the higher the number of influence sources, the higher people's compliance will be.

Pascual, Felonneau, Guéguen \& Lafaille (2014) already found no chaining effect between SP and BYAF. But in their study, SP + BYAF showed a significant effect comparatively to the control condition. So in order to determine if SP + BYAF simply produce a non-additive effect or if they produce a negligible effect, we did a replication in study 2 .

In addition, participants were asked the reason for their compliance or refusal. This exploratory methodology was employed in order to determine whether justifications vary as a function of influence sources. This procedure could be useful to interpret our results. For example, it was used for the pique technique (Santos, Leve \& Pratkanis, 1994) by (Guéguen, Meineri, Pascual, Girandola \& Silone, under press). These authors found that the number of "no reason" explanations (i.e., "I don't know") increased in the pique condition, supporting the assumption that the pique disrupts the script of refusal. 


\section{Study 2}

\section{Method}

\section{Participants}

A total of 1576 male and female passersby (528 Tunisian, 520 French and 528 Moldavian) between 18 and 70 years of age $(M=38.55$; $S D=12.7)$ participated in the study.

\section{Procedure}

Twenty-two Tunisian students (3 males and 19 females between 19 and 22 years old), two female French students (23 and 24 years old) and one female Moldavian student were the experimenters in their respective countries. They were instructed to approach passersby that were alone in pedestrian streets in the cities of Bizerte, Tunisia; Bordeaux, France; and Chișinău, Moldavia (three urban cities) to ask them to give money for cancer prevention and detection (dependent variable). The experimental design contains two independent variables: SP (presence/ absence) and BYAF (presence/absence). So the experimenters formulated their request in one of the 4 following ways:

Control formulation: "Hello Madam / Sir, the Association $X^{2}$ is collecting donations for cancer prevention and detection, would you help us please?"

Social Proof formulation: "Hello Madam / Sir, the Association X is collecting donations for cancer prevention and detection, many people have already made donations to the association, would you help us please?"

BYAF formulation: "Hello Madam / Sir, the Association X is collecting donations for cancer

\footnotetext{
${ }^{2}$ In each country, the name of a specific association was given.
} 
prevention and detection, would you help us please? But of course, you are free to

Social Proof + BYAF formulation: "Hello Madam / Sir, the Association X is collecting donations for cancer prevention and detection, many people have already made donations to the association, would you help us please? But of course, you are free to accept or refuse."

The first passerby was assigned to the first condition, the second passerby to the second condition, the third passerby to the third condition, the fourth passerby to the fourth condition, the fifth passerby to the first condition, and so on. ${ }^{3}$

Participants who went on their way before the experimenter finished reciting the formulation where not accounted for in the study. Participants who directly donated money to the experimenter were counted as compliant participants and those who did not as noncompliant participants.

After an acceptance of the request, the experimenter debriefed the participant and asked him / her to explain why he / she complied.

After a rejection of the request, the experimenter debriefed the participant and asked him / her to explain why he / she refused.

Experimenters noted on a sheet whether participants agreed or not with the request and their justification.

\section{Results}

Impact of conditions on compliance

A $2(\mathrm{SP}) \times 2(\mathrm{BYAF}) \times 3$ (country) $\times 2$ (participant gender) binary logistic regression

\footnotetext{
${ }^{3}$ Except in Tunisia where the first and second passersby were assigned to the first condition, the third and the fourth passersby to the second condition, and so on.
} 
was performed using the participants' acceptance to donate as the dependent variable. Four significant effects appeared

As in study 1, a country main effect was statistically significant, Wald (2) $=57.31, p<$ .001. More participants agreed to the request in Moldavia (39.6.6\%) than in France $(27.7 \%)$ and Tunisia $(18.2 \%)$

A weak main effect concerns SP (Wald $(1)=7.31, p<.01$ ) with $31.3 \%$ of compliance when present and $25.6 \%$ when absent $\left(\chi^{2}(1,1576)=6.31 ; p=.01 ; \varphi=.06 ; O R=1.32\right)$.

Another weak main effect concerns the BYAF (Wald $(1)=5.59, p<.02$ ) with $31.2 \%$ of compliance when present and $25.8 \%$ when absent $\left(\chi^{2}(1,1576)=5.76 ; p<.02 ; \varphi=.06 ; O R=\right.$ $1.31)$.

Finally, as in study 1, a significant interaction between SP and BYAF was observed, Wald $(1)=14.92, p<.001$. Figure 2 displays the percentage of those in each condition who agreed to give money for cancer prevention and detection. To analyze this effect of interaction, we compared each condition to each other with $\chi^{2}$ of Pearson; three significant effects were observed.

The BYAF condition generated more compliance than the control condition $\left(\chi^{2}(1,788)\right.$ $=19.41 ; p<.001 ; \varphi=.16, O R=2.08)$. In the same way, SP generated more compliance than the control condition $\left(\chi^{2}(1,788)=20.07 ; p<.001 ; \varphi=.16 ; O R=2.10\right)$. However, contrary to study 1 , the SP + BYAF condition was statistically different from the control condition $\left(\chi^{2}(1\right.$, 788) $=13.33 ; p<.001 ; \varphi=.13 ; O R=1.85)$.

None of the other main effects or interactions were statistically significant either.

Insert here figure 2

Justifications for compliance or rejection of the request 
In order to examine the types of explanations formulated by participants, we elaborated

several categories based on Knowles, Hyde \& White (2012). From this point, these categories ( 9 for rejection, and 9 for compliance with the request) were independently analyzed by three judges, as were the justifications of participants. If a judge considered a justification consistent with a category, it was coded 1 ; if not, it was coded 0 . After the three judges coded each justification, categorizations were confronted with the following criterion: we considered that for a justification to belong to a given category, it must meet an inter-judge consensus equal to $100 \%$. Of course, for each participant's justification, several categories could sometimes be present.

Table 1 presents the justifications and frequencies provided by non-compliant participants and compliant participants.

Insert here table 1

\section{Justifications for request rejection by condition}

In order to determine whether justifications depend on conditions, we conducted a multinomial logistic regression where the 9 rejection justifications were regressed on the four conditions.

Only one justification appeared statistically significant among the conditions (see figure 3); the "Hurry, no time" justification was more often provided in the control condition than in the three other conditions (Wald $(3)=7.96, p<.05)$.

Insert here figure 3

\section{Justifications for request compliance by condition}


We ran a multinomial logistic regression where the 9 acceptance justifications were regressed on the four conditions.

Only one justification appeared statistically significant among the conditions (see figure 4); the personal satisfaction to help, natural altruism justification was more often provided when SP was present than when absent (Wald $(3)=7.96, p<.05)$.

Insert here figure 4

\section{Discussion}

Whereas main effects were observed with SP and BYAF separately, as in study 1, this second study again failed to observe a chaining effect with SP and BYAF. However, contrary to the first study, in study 2 the SP + BYAF combination had an effect on compliance comparatively to the control condition. This result is consistent with observations by Pascual, Felonneau, Guéguen \& Lafaille (2014).

Concerning justifications for rejection of the request, the most commonly cited reason for declining to donate was financial difficulty (i.e., having no money to spare, not being able to afford to donate), which was the same as that observed by Knowles, Hyde \& White (2012). However, this justification was provided in the same proportions in the four conditions. Only the hurry no time justification, which was marginally cited (4.5\%), appeared differently among the conditions. We observed that this reason was invoked less when a compliance gaining strategy was employed. One possible explanation could be that when an influence strategy is employed (PS and / or BYAF), participants more often take the prosocial request into account. So, because of social desirability, it would be less possible for them to justify their rejection with a "hurry no time" explanation.

Concerning justification for compliance to the request, the most cited reason for 
donating was that charity had personal significance for the donor (e.g., donating because a family member has cancer). Again, this first justification was the same as that obtained by Knowles, Hyde \& White (2012). However, this justification is provided in the same proportions in the four conditions. Only the personal satisfaction to help, natural altruism justification, which was the third most cited (12\%), ranked differently depending on the conditions. This justification was significantly more employed when reference to the behavior of others was present (SP). This result could be due to a self-presentation strategy. Indeed, while it is clear that people often adopt others' behaviors in order to be normative, they do not want to be publicly perceived as sheep. So it is possible that under SP conditions, in order to save face (Goffman, 1974), many participants prefer to justify their acceptance by positive personal attributes. Indeed, to be thought of as a sheep with the prosocial request could be less valuable (in terms of self-presentation strategy) than helping because of personal attributes.

\section{Meta-analysis}

As regards SP and BYAF, studies 1 and 2 failed to observe a chaining effect. This result is consistent with Pascual, Felonneau, Guéguen \& Lafaille (2014). However, in study 1 SP + BYAF had no effect on compliance comparatively to the control condition but in study 2, SP + BYAF had a positive effect on compliance gaining. In order to clarify these inconsistent results, we conducted a fixed effect meta-analysis with our two studies. After decomposing the studies by study, country, sex of participants and conditions, 30 subgroups were found (see table 3 below). Column " $r$ " indicates the effect size of using the SP, BYAF or $\mathrm{SP}+\mathrm{BYAF}$ techniques relative to a direct request control expressed as a correlation such that positive correlations indicate that a strategy was more effective.

Insert here table 2 
The sample-size weighted correlations between the presence or absence of SP or the BYAF technique and the proportion of those who complied with the request were respectively $r=.14,95 \%$ CI $[0.078,0.201]$ and $r=.16,95 \%$ CI $[0.100,0.222]$ (see figure 5). These findings are consistent with a weak-sized increase in effectiveness associated with using SP or the BYAF technique instead of a direct request. It is notable that Carpenter (2013) found $r=$ .13 in his meta-analysis on BYAF.

Because the SP + BYAF combination provides a lower contingency coefficient $(r=.10,95 \%$ CI $[0.044,0.166])$, in order to determine whether mean effect sizes (r) were significantly lower in the BYAF + SP condition comparatively to the BYAF condition and the SP condition, we ran a meta-regression as recommended by Filled and Gillett (2010). In this meta-regression we entered the effect sizes as a criterion and participants' gender (Male vs Female), countries (France vs. Tunisia vs. China vs. Moldavia) and conditions (BYAF+SP vs $\mathrm{SP}$ and BYAF) as categorical predictors. More precisely, BYAF+SP was condition 1 and SP and BYAF were aggregated in condition 2. The results indicate non-significant effects of conditions $\left(\chi^{2}(1)=0.57, p=.44, n s\right)$, participants' gender $\left(\chi^{2}(1)=0.025, p=.87, n s\right)$ and countries $\left(\chi^{2}(3)=6.56, p=.09, n s\right)$. These results indicate that none of these variables moderate the effect of these influence techniques.

\section{General discussion and conclusion}

Our results suggest that we cannot conclude that $\mathrm{SP}+\mathrm{BYAF}$ diminished the compliance effect. However, our data provide strong evidence that chaining did not work with SP and BYAF. As we hypothesized, because of an antinomy between external pressure (SP) and internal pressure (BYAF), the two kinds of influence sources studied (internal vs external) produced a non-additive effect on compliance. Because of this contradiction, the two processes have no additional effect on compliance; whereas in the framework of a chaining 
hypothesis, the higher the number of influence sources, the higher people's compliance will be.

Finally, we observed that SP, BYAF and SP + BYAF produced behavioral compliance in the same proportions. However, while their sources of influence are different, in study 2 participants' justifications after complying with or rejecting the request were substantially the same.

Concerning rejection, we only observed that the "hurry, no time" justification was higher in the control condition. It is possible that when a compliance gaining procedure is employed (SP and / or BYAF), more attention is required by participants to prosocial requests and it could be less socially acceptable to say they have no time to help others for a cause such as cancer prevention.

For compliance, we only observed that the "personal satisfaction to help, natural altruism" justification was higher when SP was employed. Such a result appears to be a paradox because objectively, with SP, the source of influence is external to participants. It is possible that participants are aware they are being influenced by SP (Nolan, Schultz, Cialdini, Goldstein, \& Griskevicius, 2008), but they feel uncomfortable confessing this to the experimenter. So, in order to be seen as an altruistic person rather than an easily influenced one, most of them choose to justify their compliance by a personal attribute.

In conclusion, our data suggest that chaining is not as programmed as Howard (1995) suggested. It is possible that when sources of influence are incompatible, chaining is disrupted. This is clearly the case with SP and BYAF, and future research should explore this with other compliance gaining strategies.

For example, Reingen (1978) observed no additive effect when combining door-inthe-face and the "even a penny will help" technique. The author concludes that "even a penny will help" is sufficient in itself to make it difficult for participants to refuse to donate money. 
In another example, studying social labeling and touch in a foot-in-the-door situation,

Goldman, Kiyohara and Pfannensteil (1985) found that when taken separately, positive social labeling and touch increased compliance but that it decreased when positive social labeling and touch were combined. In this case, the authors suggest that participants may have simply believed that the confederate was a flatterer, which would alter their self-image.

In the same way, Meineri, Dupré and Guéguen (2016) failed to observe any chaining effect when combining door-in-the-face with BYAF. An interpretation could be that door-inthe-face led to stronger feelings of obligation to donate (Abrahams \& Bell, 1994), which refers to an external source of influence (such as SP), whereas BYAF refers to an internal source of influence.

\section{References}

Abrahams, M. \& Bell, R. (1994). Encouraging charitable contributions: an examination of three models of door-in-the-face compliance. Communication Research, 21(2), 131-153. DOI: $10.1177 / 009365094021002001$

Asch, S. E. (1951). Effects of group pressure upon the modification and distortion of judgments. In H. Guetzkow (Ed.), Groups, leadership and men. Pittsburgh, PA: Carnegie Press.

Biel, A., Borgstede, C. V., \& Dahlstrand, U. (1999). Norm perception and cooperation in large scale social dilemmas. In M. Foddy, M. Smithson, S. Schneider, \& M. Hogg (Eds.), Resolving social dilemmas: Dynamic, structural, and intergroup aspects (pp. 245-252). Psychology Press.

Brehm, J. W. (1966). A theory of psychological reactance. New York: Academic Press.

Carpenter, C. J. (2013). A meta-analysis of the effectiveness of the "but you are free" compliance-gaining technique. Communication Studies, 64(1), 6-17. DOI: 
10.1080/10510974.2012.727941

Cialdini, R. B. (2003). Crafting normative messages to protect the environment. Current Directions in Psychological Science, 12, 105-109. DOI: 10.1111/1467-8721.01242

Cialdini, R. B. (2005). Basic social influence is underestimated. Psychological Inquiry, 16(4), 158-161. DOI:10.1207/s15327965pli1604_03

Cialdini, R. B., \& Goldstein, N. (2004). Social influence: Compliance and conformity. Annual Review of Psychology, 55, 591-621. DOI: 10.1146/annurev.psych.55.090902.142015

Cialdini, R. B., Reno, R. R., \& Kallgren, C. A. (1990). A focus theory of normative conduct: Recycling the concept of norms to reduce littering in public places. Journal of Personality and Social Psychology, 58, 1015-1026. DOI: 10.1037/0022-3514.58.6.1015

Cialdini, R. B., Wosinska, W., Barrett, D. W., Butner, J., \& Gornik-Durose, M. (1999). Compliance with a request in two cultures: The differential influence of social proof and commitment/consistency on collectivists and individualists. Personality and Social Psychology Bulletin, 25, 1242-1253. DOI: 10.1177/0146167299258006

Dolinski, D. (2016). Techniques of Social Influence: The Psychology of Gaining Compliance. New York: Routledge.

Dufourcq-Brana, M., Pascual, A., \& Guéguen, N. (2006). Déclaration de liberté et pied-dansla-porte. Revue Internationale de Psychologie Sociale, 19(3/4), 173-187.

Fointiat, V. (2000). The foot-in-the-mouth versus door-in-the-face requests. The Journal of Social Psychology, 140, 2, 264-266. DOI: 10.1080/00224540009600468

Field, A. P., \& Gillett, R. (2010). How to do a meta-analysis. British Journal of Mathematical and Statistical Psychology, 63, 665-694. DOI:10.1348/000711010X502733

Freedman, J., \& Fraser, S. (1966). Compliance without pressure: The foot-in-the-door technique. Journal of Personality and Social Psychology, 4, 195-202. DOI: $10.1037 / \mathrm{h} 0023552$ 
Goffman, E. (1974). Les rites d'interaction. Paris: Les Editions de minuit.

Goldman, M. (1986). Compliance emplolying a combined foot-in-the-door and door-in-theface procedure. The Journal of Social Psychology, 126(1), 111-116. DOI: $10.1080 / 00224545.1986 .9713577$

Goldman, N., Kiyohara, O. \& Pfannensteil, D.A. (1985). Interpersonal touch, social labeling, and the foot-in-the-door effect. The Journal of Social Psychology, 125(2), 143-147. DOI: $10.1080 / 00224545.1985 .9922866$

Goldman, M., Seever, M. \& Seever, M. (1982). Social labeling and the foot-in-the-door effect. The Journal of Social Psychology, 117, 19-23. DOI: $10.1080 / 00224545.1982 .9713402$

Goldstein, N., \& Cialdini, R. B. (2007). Using social norms as a lever of social influence. In A. Pratkanis (Ed.), The science of social influence: Advances and future progress (pp. 167-191). Philadelphia, PA: Psychology Press.

Guéguen, N., Joule, R. V., Halimi-Falkowicz, S., Pascual, A., Fischer-Lokou, J., \& DufourcqBrana, M. (2013). I'm freebut I'll comply with your request: Generalization and multidimensional effects of the "evoking freedom" technique. Journal of Applied Social Psychology, 43, 116-137. DOI: 10.1111/j.1559-1816.2012.00986.x

Guéguen, N., Meineri, S., Martin, A. \& Grandjean I. (2010). The combined effect of the footin-the-door technique and the « but you are free » technique: an evaluation on the selective sorting of household wastes. Ecopsychology, 2(4), 231-237. DOI: 10.1089/eco.2009.0051

Guéguen, N., Meineri, S., Pascual, A., Girandola, F. \& Silone, F. (under press) Hey buddy, can you give me thirty-seven seconds of your time? Extension of the pique technique to a non-monetary solicitation and test of justification for compliance. Current Psychology. DOI: 10.1007/s12144-015-9324-z 
Guéguen, N., \& Pascual, A. (2000). Evocation of freedom and compliance: The "but you are free of' technique. Current Research in Social Psychology, 5(18), 264-270.

Howard, D. (1995). «Chaining» the use of influence strategies for producing compliance behavior. Journal of Social Behavior and Personality, 10(1), 169-195.

Joule, R.V. (1987). Tobacco deprivation: the foot-in-the-door technique versus the low-ball technique. European Journal of Social Psychology, 17, 361-365. http://psycnet.apa.org/doi/10.1002/ejsp.2420170311

Joule, R. V., \& Beauvois, J. L. (1998). La soumission librement consentie. Paris: PUF.

Kiesler, C. A. (1971). The psychology of commitment. Experiments liking behavior to belief. New York: Academic Press.

Knowles, S.R., Hyde, M.K. \& White, K.M. (2012). Predictors of young people's charitable intentions to donate money: An extended theory of planned behavior perspective. Journal of Applied Social Psychology, 42(9), 2096-2110. DOI: 10.1111/j.15591816.2012.00932.x

Meineri, S., Dupré, M., Guéguen, N. \& Vallée, B. (2016). Door-in-the-face and But-you-arefree: Testing the effect of combining two no-pressure compliance paradigms. Psychological Reports, 119(1), 276-89. DOI: 10.1177/0033294116657064

Nolan, J. M., Schultz, P. W., Cialdini, R. B., Goldstein, N. J., \& Griskevicius, V. (2008). Normative social influence is underdetected. Personality and Social Psychology Bulletin, 34(7), 913-923. DOI: 10.1177/0146167208316691

Pascual, A., Felonneau, M.L., Guéguen, N. \& Lafaille, E. (2014). Conformity, obedience to authority and compliance without pressure to control cigarette butt pollution. Social Influence, 9(2), 83-98. DOI: 10.1080/15534510.2013.778214

Pratkanis, A. R. (Eds.). (2007). The science of social influence: advances and future progress. Frontiers of Social Psychology. Philadelphia, PA: Psychology Press. 
Reingen, P. H. (1978). On inducing compliance with requests. The Journal of Consumer Research, 5, 96-102. DOI: http://dx.doi.org/10.1086/208720

Samson, L. (2009). Soumission librement consentie: études interculturelles: France, Roumanie, Russie: procédure de toucher versus, procédure de "vous-êtes-libre-de" [Voluntary compliance: Intercultural studies: France, Romania, and Russia: Touch technique versus “'you are free?”]. Unpublished doctoral dissertation, Université de Provence Aix-Marseille I, Aix-en-Provence, France.

Santos, M. D., Leve, C., \& Pratkanis, A. R. (1994). Hey buddy, can you spare seventeen cents? Mindful persuasion and the pique technique. Journal of Applied Social Psychology, 24, 755-764. DOI: 10.1111/j.1559-1816.1994.tb00610.x

Shearman, S.M. \& Yoo, J.H. (2007). “Even a penny will help!”: Legitimization of paltry donation and social proof in soliciting donation to a charitable organization. Communication Research Reports, 24(4), 271-282. DOI: 10.1080/08824090701624148

Thøgersen, J. (2006). Norms for environmentally responsible behaviour: An extended taxonomy. Journal of Environmental Psychology, 26, 247-336. DOI:10.1016/j.jenvp.2006.09.004 
Social Proof and «But you are Free »

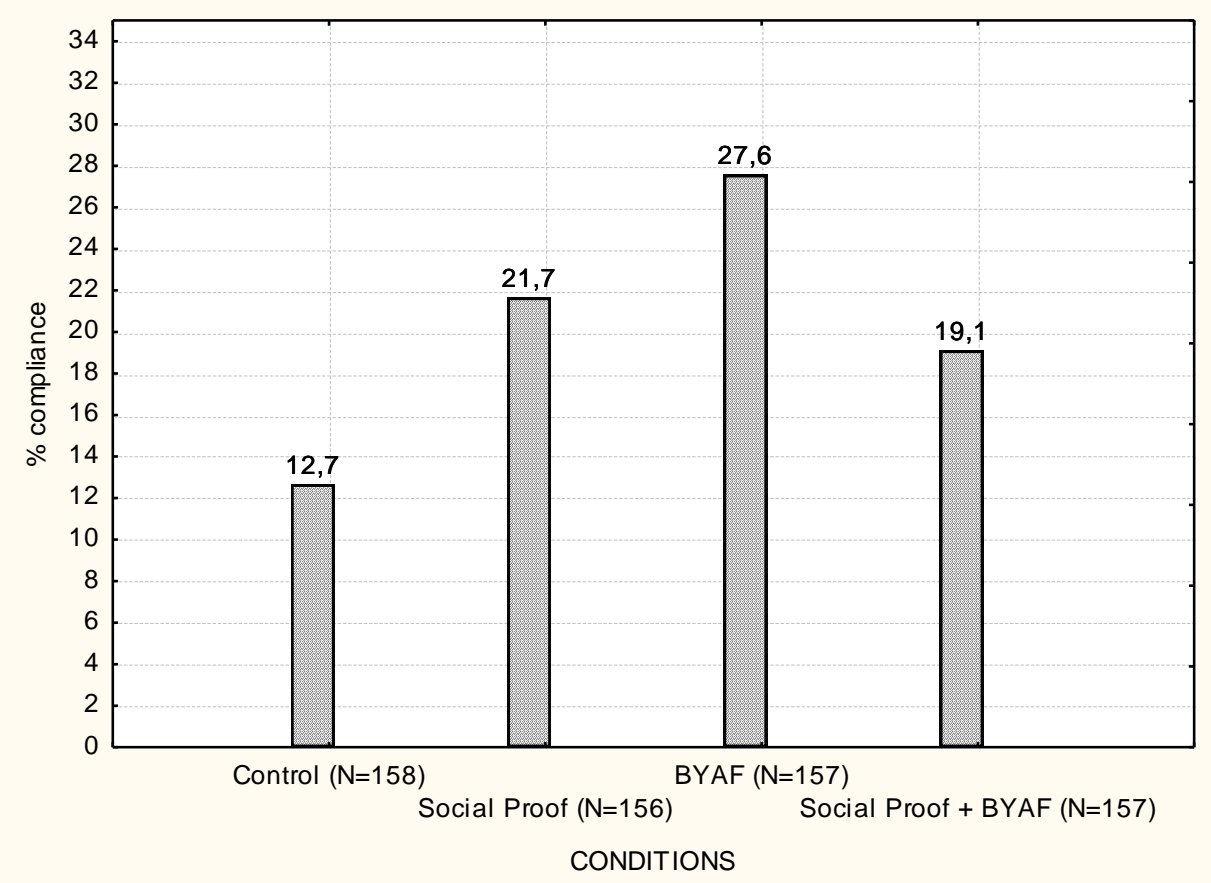

Figure 1. Impact of Social Proof and BYAF on compliance gaining. 
Social Proof and «But you are Free »

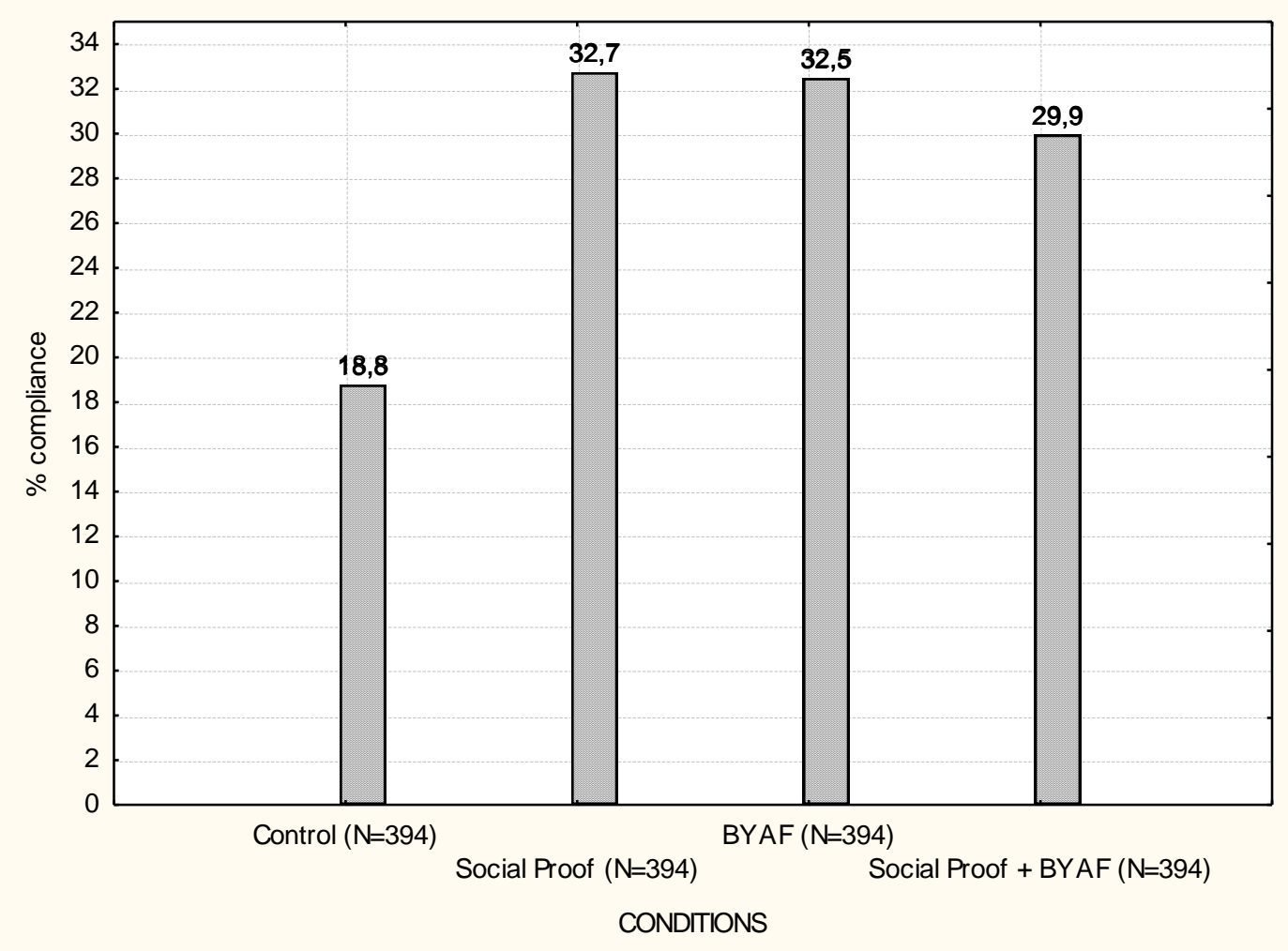

Figure 2. Impact of Social Proof and BYAF on compliance gaining. 


\begin{tabular}{|c|c|c|c|c|c|}
\hline $\begin{array}{c}\text { Justifications for } \\
\text { decision not to } \\
\text { donate Money } \\
(N=1127 \\
\text { participants }) \\
\end{array}$ & $\%$ & example & \begin{tabular}{|c|} 
Justifications for \\
decision to donate \\
Money \\
$(N=449$ \\
participants $)$ \\
\end{tabular} & $\%$ & example \\
\hline $\begin{array}{r}\text { Financial } \\
\text { difficulties (i.e., no } \\
\text { money to spare, } \\
\text { can't afford it) }\end{array}$ & 19.0 & $\begin{array}{c}\text { "I am poor and needy. I } \\
\text { cannot help } »\end{array}$ & $\begin{array}{r}\text { Concerned by } \\
\text { cancer (self or } \\
\text { relatives) }\end{array}$ & 22.0 & $\begin{array}{l}\text { «My family is very } \\
\text { concerned by cancer » }\end{array}$ \\
\hline $\begin{array}{l}\text { Not having spare } \\
\text { change when asked }\end{array}$ & 15.5 & $\begin{array}{c}\text { «y wallet is not with } \\
\text { me }\end{array}$ & Support act & 19.8 & $\begin{array}{l}\text { «I support the } \\
\text { associative actions and } \\
\text { I wanted to help» }\end{array}$ \\
\hline $\begin{array}{l}\text { Don't trust the } \\
\text { money goes to } \\
\text { those who need it }\end{array}$ & 10.8 & $\begin{array}{c}\text { Excuse me, you will } \\
\text { not convince me. I do } \\
\text { not do gift, I do not } \\
\text { trust } »\end{array}$ & $\begin{array}{r}\text { Personal } \\
\text { satisfaction to help, } \\
\text { natural altruism }\end{array}$ & 12.0 & $\begin{array}{l}\text { « really enjoy helping } \\
\text { others } ~\end{array}$ \\
\hline $\begin{array}{l}\text { already donate to } \\
\text { charitable causes }\end{array}$ & 7.8 & $\begin{array}{l}\text { «I already have } \\
\text { participated in charity } \\
\text { work» }\end{array}$ & $\begin{array}{r}\text { apologizes for the } \\
\text { low amount }\end{array}$ & 10.5 & $\begin{array}{c}\text { «If I had more money I } \\
\text { would have given } \\
\text { more }\end{array}$ \\
\hline Reference to God & 7.0 & $\begin{array}{l}\text { "It will be for another } \\
\text { time God willing » }\end{array}$ & $\begin{array}{r}\text { Urgency / } \\
\text { Importance of the } \\
\text { cause }\end{array}$ & 10.0 & $\begin{array}{l}\text { «Our health is the most } \\
\text { important thing » }\end{array}$ \\
\hline $\begin{array}{r}\text { No interest in or not } \\
\text { knowing about the } \\
\text { cause the charity is } \\
\text { collecting money } \\
\text { for }\end{array}$ & 5.2 & $\begin{array}{l}\text { «It really does not affect } \\
\text { me, I do not feel } \\
\text { concerned } »\end{array}$ & $\begin{array}{r}\text { A cancer could } \\
\text { happen (self or } \\
\text { relatives) }\end{array}$ & 7.8 & $\begin{array}{l}\text { «'m not immune to } \\
\text { catch cancer } »\end{array}$ \\
\hline Hurry, no time & 4.5 & $\begin{array}{c}\text { «I'm in a hurry my } \\
\text { wife is waiting for me }\end{array}$ & $\begin{array}{r}\text { Sensitive to the } \\
\text { cause }\end{array}$ & 5.8 & $\begin{array}{c}\text { "This case interests } \\
m e »\end{array}$ \\
\hline $\begin{array}{c}\text { Promise help or } \\
\text { deferred gifts }\end{array}$ & 4.3 & $\begin{array}{l}\text { "I will come to the } \\
\text { association to donate }\end{array}$ & $\begin{array}{r}\text { Reference to God / } \\
\text { religion }\end{array}$ & 5.3 & $\begin{array}{l}\text { «od wants us to help } \\
\text { our neighbor } ~\end{array}$ \\
\hline $\begin{array}{r}\text { None } \\
\text { argumentation }\end{array}$ & 1.4 & Refuse to comment & $\begin{array}{r}\text { Positive perception } \\
\text { of the solicitor }\end{array}$ & 5.3 & $\begin{array}{l}\text { "You inspire me } \\
\text { confidence » }\end{array}$ \\
\hline
\end{tabular}

Note. Participants may have provided multiple reasons for not donating or donating.

Tables 1. Justifications for decision not to donate Money and donate money 
Social Proof and «But you are Free »

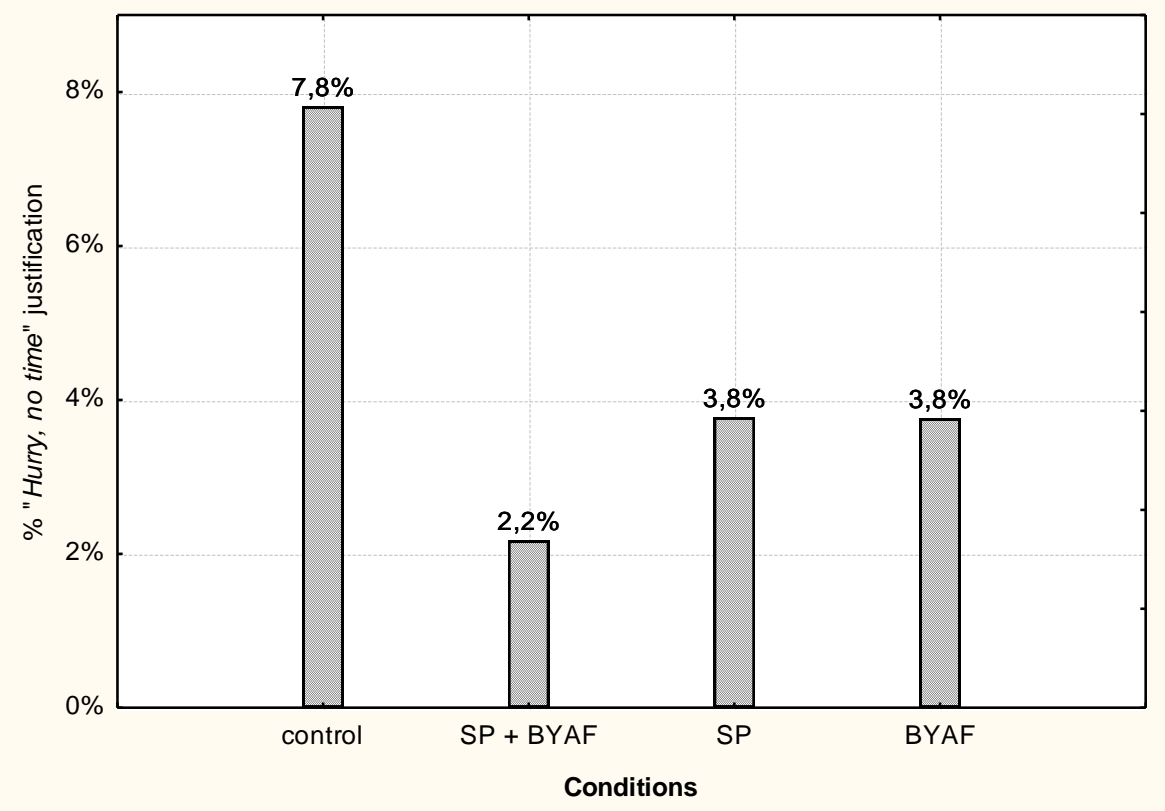

Figure 3. "hurry, no time" justification to reject the request among conditions 


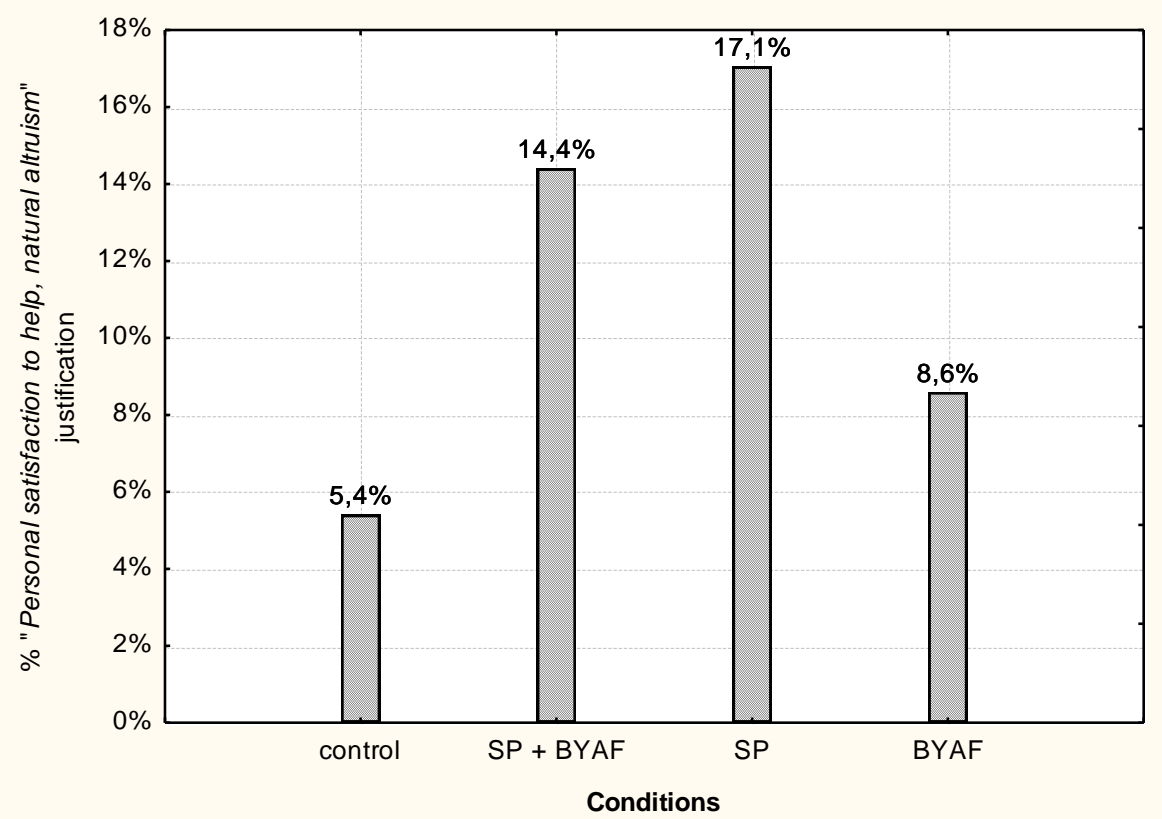

Figure 4. "personal satisfaction to help, natural altruism" justification to accept the request among conditions 
Social Proof and «But you are Free »

1

\begin{tabular}{|c|c|c|c|c|}
\hline Study & Country & Sex participant & condition & $\mathbf{r}$ \\
\hline \multirow{12}{*}{1} & \multirow{6}{*}{ France } & \multirow{3}{*}{ men } & SP & 0,13 \\
\hline & & & BYAF & 0,3 \\
\hline & & & $\mathrm{BYAF}+\mathrm{SP}$ & 0,26 \\
\hline & & \multirow{3}{*}{ women } & SP & 0,2 \\
\hline & & & BYAF & 0,2 \\
\hline & & & $\mathrm{BYAF}+\mathrm{SP}$ & 0 \\
\hline & \multirow{6}{*}{ China } & \multirow{3}{*}{ men } & $\mathrm{SP}$ & 0,01 \\
\hline & & & BYAF & 0,14 \\
\hline & & & $\mathrm{BYAF}+\mathrm{SP}$ & 0,04 \\
\hline & & \multirow{3}{*}{ women } & $\mathrm{SP}$ & 0,11 \\
\hline & & & BYAF & 0,05 \\
\hline & & & $\mathrm{BYAF}+\mathrm{SP}$ & 0 \\
\hline \multirow{18}{*}{2} & \multirow{6}{*}{ Tunisia } & \multirow{3}{*}{ men } & SP & 0,04 \\
\hline & & & BYAF & 0,06 \\
\hline & & & $\mathrm{BYAF}+\mathrm{SP}$ & 0,02 \\
\hline & & \multirow{3}{*}{ women } & SP & 0,18 \\
\hline & & & BYAF & 0,08 \\
\hline & & & $\mathrm{BYAF}+\mathrm{SP}$ & 0,02 \\
\hline & \multirow{6}{*}{ France } & \multirow{3}{*}{ men } & $\mathrm{SP}$ & 0,24 \\
\hline & & & BYAF & 0,17 \\
\hline & & & $\mathrm{BYAF}+\mathrm{SP}$ & 0,15 \\
\hline & & \multirow{3}{*}{ women } & SP & 0,29 \\
\hline & & & BYAF & 0,22 \\
\hline & & & $\mathrm{BYAF}+\mathrm{SP}$ & 0,28 \\
\hline & \multirow{6}{*}{ Moldavia } & \multirow{3}{*}{ men } & SP & 0,14 \\
\hline & & & BYAF & 0,25 \\
\hline & & & $\mathrm{BYAF}+\mathrm{SP}$ & 0,2 \\
\hline & & \multirow{3}{*}{ women } & $\mathrm{SP}$ & 0,07 \\
\hline & & & BYAF & 0,14 \\
\hline & & & $\mathrm{BYAF}+\mathrm{SP}$ & 0,08 \\
\hline
\end{tabular}

Table 2: Contingency coefficient decomposition in study 1 and 2 